Penultimate draft. For published version see:

https://doi.org/10.1111/mila.12398

SUBMITTED ARTICLE

\title{
Tracking representationalism and olfaction
}

Błażej Skrzypulec

Institute of Philosophy, Jagiellonian University, Kraków, Poland

\section{Correspondence}

Błażej Skrzypulec

Institute of Philosophy, Jagiellonian University, Grodzka 52, 31-044, Kraków, Poland

Email: blazej.skrzypulec@uj.edu.pl

\section{Funding information}

The work was supported by the National Science Center (Poland) grant 2018/31/D/HS1/00363.

While philosophers of perception develop representational theories of olfactory experiences, there are doubts regarding whether features of olfactory perception can be accommodated within the representationalist framework. In particular, it is argued that the function of olfaction is not to represent stimuli but rather to evaluate it. The paper claims that the major representational accounts of olfaction have problems in accommodating the evaluative aspects of olfactory phenomenology. However, an alternative position, named "olfactory evaluativism," is proposed which is free of 
these problems and may serve as a foundation for further developments of representational approach to olfactory experiences.

\section{KEYWORDS}

olfaction, tracking representationalism, representational content, phenomenal character, perception, olfactory valence

\section{INTRODUCTION}

According to representationalism, one of the most influential contemporary approaches to perception, phenomenal character of perceptual experiences is determined by their representational content such that phenomenal differences can be explained by differences in content (e.g., Cutter \& Tye, 2011; Green, 2016; Wu, 2011). Because content is commonly understood in terms of accuracy conditions (see Siegel, 2010), the representationalist position entails that the differences in the phenomenal "what is it like" aspect of perceptual experiences occur in virtue of differences in conditions of accuracy. One of the biggest challenges for representationalist theories is the problem of content determination (e.g., Hutto \& Myin, 2013; Miłkowski, 2015). This problem consists of establishing the content of considered perceptual experiences or, in other words, their accuracy conditions. For instance, a perceptual experience $\mathrm{S}$ may sometimes occur when a property $\mathrm{F}$ is instantiated by an object in the environment and sometimes when a property $\mathrm{P}$ is instantiated. In consequence, a question arises: How to determine whether the state $\mathrm{S}$ represents $\mathrm{F}$ and so S's occurrence when $\mathrm{P}$ is present is a form of representational mistake, or conversely $\mathrm{S}$ represents $\mathrm{P}$ and so S's occurrence when $\mathrm{F}$ is instantiated is a mistake, or $\mathrm{S}$ represents $\mathrm{F}$ or $\mathrm{P}$, and so the 
representation is accurate in both cases. The usual way to resolve the problem of content determination is to postulate that a state $\mathrm{S}$ represents those elements which correlate with $\mathrm{S}$ or cause S's occurrence when some normative clause is satisfied. For instance, the state S may represent those elements which cause its occurrence when perceptual conditions are optimal, or when the system generating $\mathrm{S}$ successfully fulfils its proper biological function (see Millikan 1989). One such idea has been formulated by Cutter and Tye (2011) under the name "tracking theory of intentionality":

Tracking theory of intentionality: Tokens of a state $\mathrm{S}$ in an individual $x$ represent that $p$ in virtue of the fact that: under optimal conditions, $x$ tokens $\mathrm{S}$ iff $p$, and because $p$.

A combination of some form of tracking theory of intentionality with a core representationalist thesis about the determination of phenomenal character by representational content constitutes "tracking representationalism" which is a mainstream, naturalistic approach to perceptual experiences. According to such a position, differences in the subjective phenomenology of experiences are explained by differences in their representational content, and content of experiences is determined by systematic relations, occurring under some form of optimal conditions, between an experience and environmental elements.

While tracking representationalist theories have been primarily developed in the context of visual modality, they are also applied to other senses. In particular, given the recent increase of interest in olfactory modality within philosophy of perception (e.g., Aasen, 2019; Batty, 2010; Millar, 2019; Mizrahi, 2014; Skrzypulec, 2021), olfaction is also interpreted in tracking representationalist terms, even if traditionally olfactory experiences have often been characterised as nonrepresentational (Lycan, 1996; Peacocke, 1983). The most developed 
such theory is "molecular structure theory" proposed by Young $(2016,2019,2020)$, according to which olfactory experiences track changes concerning molecular compositions of olfactory plumes, rations of these structures, and their concentrations. On the other hand, there are also authors who, often relying on current empirical knowledge concerning olfaction, argue that due to the peculiarities of the olfactory system, tracking representationalism is implausible as a proper theory of olfaction (Barwich, 2018, 2019; Castro \& Seeley, 2014; Cooke \& Myin, 2011; Keller, 2016). In consequence, it is proposed that the function of olfaction is not to represent the properties of stimuli but rather to evaluate stimuli, recognise their significance for the organism and motivate an adaptive behaviour.

The goal of the paper is to investigate whether a tracking representationalist theory can be successfully applied to olfactory experiences. I start, in Section 2, by formulating two general challenges that face tracking representationalism in the context of olfactory perception. Subsequently, in sections 3 and 4, I present the molecular structure theory, which is the major representationalist theory of olfaction, and evaluate whether it is able to answer the formulated challenges. It is argued that the molecular structure theory has significant problems in accounting for the considered challenges, as it does not have resources allowing for a representational explanation of changes in olfactory valence. These problems undermine the project of representationalist treatment of olfactory experiences. However, in sections 5 and 6, I propose a further development of the molecular structure theory which leads to an account named "olfactory evaluativism," that is able to answer the relevant challenges. According to my proposition, inspired by the evaluativist approaches in philosophy of pain (see Bain, 2013; Cutter \& Tye, 2011; O’Sullivan \& Schroer, 2012), the molecular structure theory should be supplemented by a representationalist account of olfactory relational, evaluative properties, including those regarding olfactory pleasure and displeasure. The proposed theory, which claims that olfactory experiences represent not merely molecular 
structures but also their significance for a subject, demonstrates that the peculiarities of olfactory perception can be accommodated within a tracking representationalist framework.

\section{TWO OLFACTORY CHALLENGES}

According to tracking representationalism, (a) phenomenal character of a perceptual experience $S$ is determined by its content, and (b) the content of $S$ is determined by a relation between occurrences of $S$ and the presence of certain elements in the environment influencing the perceptual system. The point (a) is a "phenomenal determination thesis" which, in the context of olfactory experiences, means that it should be possible to explain olfactory phenomenal differences by reference to differences in olfactory representational content. According to point (b), which may be named "content determination thesis," there should be a systematic relation between occurrence of olfactory experiences and presence of olfactory stimuli such that it is justified to propose that the content of an experience characterises properties of olfactory stimuli, for instance chemical structures of molecules composing olfactory plumes.

In consequence, one may attempt to refute the olfactory tracking representationalism in two general ways. It can first be done by refuting content determination thesis. This is done by showing that the relation between the occurrence of olfactory experiences and the presence of olfactory stimuli does not properly determine that the olfactory representational content concerns the presence of olfactory stimuli with certain properties. Second, the phenomenal determination thesis can be rejected by showing that in some cases variations in olfactory phenomenal character cannot be explained by reference to variations in content.

Within the contemporary literature regarding empirically-informed philosophy of olfactory perception, one can identify two main challenges threatening representationalist 
treatment of olfactory experiences. The first is the "nonlinearity challenge" which concerns the relation between similarities of chemical structures and phenomenal similarities of olfactory experiences (see Barwich, 2018, 2019; Keller, 2016). In a modality such as vision, stimuli more similar in respect of their physical, perceptible properties are usually also experienced as being more similar to each other. For instance, lines that are more similar in terms of orientation are experienced, ceteris paribus, as more similar than those which are separated by larger differences. However, such a strict relationship is not present in the case of olfaction where stimuli with similar molecular structures often cause significantly differing experiences, while structurally distinct substances often cause phenomenally similar experiences. For instance, musk odour is realised by at least several significantly distinct structures (see Pautz, 2010, 2014; Sell, 2006 for additional examples).

The nonlinearity challenge makes the content determination thesis less plausible by undermining the claim that olfactory representational contents are determined by relations between occurrences of olfactory experiences and the presence of certain molecules. Such systematic relations, in virtue of which olfaction tracks the chemical structures in a changing chemical environment, plausibly lead to a situation in which similar structures are represented in a similar way. This is because a properly developed system of representations should model the relations between stimuli, such that it allows classification of similar stimuli, facilitates similar actions toward stimuli with similar properties, and provides justification for similar beliefs when similar stimuli are encountered.

However, a strong correlation between structural similarity and phenomenal similarity does not seem to be present in the case of human olfaction, which may suggest that the function of olfaction is not to represent physical properties of olfactory stimuli. Furthermore, the nonlinearity challenge also constitutes a problem for the phenomenal determination thesis. If similarities between represented chemical structures do not fully explain similarities 
between olfactory experiences, a question arises of what the additional factors that determine the similarities of olfactory phenomenal character are. In accordance with the phenomenal determination thesis, a representational theory of olfaction should be able to identify these additional factors with some elements of representational content.

The second "independency challenge" also threatens the phenomenal determination thesis by proposing factors in virtue of which olfactory phenomenology changes in a way which is not associated with modifications of content. Many such factors concern the variations of context in which a chemical stimulus is presented. For instance, it is observed that the same chemical substance may cause phenomenally distinct experiences depending on the presence of the other substances in the surroundings (see Stevenson, 2009; Yeshurun \& Sobel, 2010). Similarly, it is well-recognised that the same chemical stimuli may be experienced in a distinct way among individuals. This happens because there are significant differences concerning the genetically determined functioning of olfactory receptors across a population (see Trimmer et al., 2019; Frumin et al., 2013). Furthermore, there are changes in phenomenology of olfactory experiences which may occur due to olfactory learning and memory (see Stevenson et al., 2010; Wilson \& Stevenson, 2006). The independency challenge also arises from the observation that olfactory phenomenology can change in virtue of a subject's beliefs and expectations, independently of changes concerning chemical stimuli (see Barwich, 2020; Keller, 2016; Wilson \& Stevenson, 2006). In consequence, it seems that various olfactory phenomenal changes are not associated with modification of representational content.

Overall, the nonlinearity challenge provides a reason to doubt whether olfactory experiences have content concerning structures of chemical stimuli. The independency challenge threatens the phenomenal determination thesis by providing examples in which 
phenomenal character changes without modification of the representational character due to contextual variations or factors such as top-down influences.

\section{MOLECULAR STRUCTURE THEORY}

The molecular structure theory, developed by Benjamin Young, is a major representationalist theory of human olfaction. In the paper introducing the theory, Young (2016, pp. 8-9) claims that "object of olfactory perception is the molecular structure of chemical compounds within odour plumes," and that "every olfactory quality can be accounted for in terms of the molecular structure of chemical compounds within odour plumes." The first statement suggests a form of content determination thesis such that an olfactory representation is accurate if its occurrence correlates with the presence of its proper object, which is a certain chemical structure. The second statement establishes the phenomenal determination thesis by postulating that olfactory phenomenal character is determined by content concerning the presence of certain molecular structures.

While the initial formulation of the molecular structure theory suggested that phenomenology of olfactory experiences is fully determined by represented structures, the further developments of the theory have introduced additional factors (Young, 2019, 2020). In particular, differences between olfactory phenomenal characters correspond not merely to the differences in molecular structures present within an olfactory plume but also to the differences in proportions of structures and their concentrations in a plume. For instance, according to the molecular structure theory, an experience of an olfactory plume composed of molecules with structures $\mathrm{X}$ and $\mathrm{Y}$ at a ratio of 2:1 can be different from an experience of a plume in which the proportion of $\mathrm{X}$ and $\mathrm{Y}$ is reversed. Similarly, a plume composed of low concentration of $\mathrm{X}$ and $\mathrm{Y}$ structures at a ratio of 2:1 can be experienced differently than a 
plume composed of high concentration of $\mathrm{X}$ and $\mathrm{Y}$ structures in the same ratio. This means the content of olfactory experiences should not be characterised simply as "there are structures $\mathrm{X}, \ldots, \mathrm{Y}$ " but rather as "there are structures $\mathrm{X}, \ldots, \mathrm{Y}$, in ratio $\mathrm{R}$, having concentrations $\mathrm{c}(\mathrm{X}), \ldots, \mathrm{c}(\mathrm{Y})$ ". In consequence, not every phenomenal difference between olfactory experiences has to correspond to differences in represented structures, but there are also phenomenal differences corresponding to distinctions concerning proportions between structures and their concentrations within an olfactory plume.

Furthermore, the molecular structure theory allows for changes in olfactory phenomenology which arise due to the subject's background knowledge and expectations (Young, 2019). In particular, such top-down factors may be of high importance in cases of experiences involving olfactory figure/ground discrimination (Young, 2016, 2020) and grouping (Young, 2019, 2020). For instance, when molecular structures $\mathrm{X}$ and $\mathrm{Y}$ are olfactorily perceived it is possible, at least in the case of certain structures, to experience two odours, one corresponding to X-molecules and the second corresponding to Y-molecules, such that one is a "figure" while the other constitutes olfactory "background" (see Gottfried, 2010; Millar, 2019; Stevenson \& Wilson, 2007). In this case, two phenomenally distinct experiences are possible, one in which the X-related odour is a figure and the second in which the Y-related odour has this status. Similarly, when several structures are simultaneously perceived, let's say X, Y, and Z, they may be perceptually grouped in such a way that one experiences two odours, one determined by $\mathrm{X}$ and the second determined by $\mathrm{Y}$ and $\mathrm{Z}$. However, the same structures may also be grouped differently giving rise to phenomenally distinct experiences, for instance to an experience in which one odour is determined by $\mathrm{X}$ and $\mathrm{Y}$ while the second is determined by $\mathrm{Z}$.

One may suppose that by allowing phenomenal changes determined by background knowledge and expectations, the molecular structure theory diverts from the representational 
orthodoxy. However, it is not necessarily the case as there are important positions aimed towards providing a representationalist interpretation of phenomenal changes associated with figure/ground discrimination and grouping. For instance, a square-shaped visual stimulus composed of equidistant dots can be experienced in two phenomenally distinct ways corresponding to two distinct perceptual groupings: as constituted by rows of dots, or as constituted by columns of dots. Despite the fact that in both cases the physical stimulus is the same, each phenomenally distinct experience may also be associated with distinct content. For instance, in each case the perceived object may be represented as composed of distinct proper parts: columns in one case and rows in the other (see Green, 2016 for this particular solution and Nanay, 2010; Peacocke, 1992; Tye, 2002; Wu, 2014 for alternative representational approaches).

While Young does not endorse any particular representational solutions concerning figure/ground discrimination and grouping, it seems plausible that various representational ideas can be also applied in the context of human olfaction. For instance, it may be postulated that olfaction, in addition to representing the presence of molecular structures, their rations, and concentrations, also represents certain relations between perceived structures which allow presentation of distinct perceptual organisations of the same stimulus. For example, structures $\mathrm{X}$ and $\mathrm{Y}$ may be represented as standing in an asymmetric relation which determines their figure/ground status. Furthermore, a difference in representational content may arise from the fact that odours having a figure-status are represented in a more detailed way than those constituting olfactory ground. Similarly, in the case of olfactory grouping, an experience presenting two odours, one determined by a combination of $\mathrm{X}$ and $\mathrm{Y}$ structures and the second determined by a $\mathrm{Z}$ structure, can have distinct content from an experience presenting an XZ-odour and a Y-odour, since each of these experiences may represent structures as 
standing in a separate patter of relations determining the structures that compose a single odour and those that belong to distinct odours.

Overall, according to molecular structure theory, the phenomenal character of olfactory experiences is determined by four factors. First, olfactory experiences may have distinct phenomenology as they represent the presence of distinct molecular structures. Second, phenomenal differences can arise due to representing ratios of structures. Third, even if structures and their rations are the same, olfactory phenomenology may vary due to differences in concentration. Finally, in virtue of possessed background knowledge and expectations, the same structures may be represented as standing in distinct organisational relations determining their figure/ground status and division between distinct odours. In the subsequent section, I argue that despite its significant explanatory power, the molecular structure theory has problems in accounting for nonlinearity and independency challenges.

\section{MOLECULAR STRUCTURE AND STIMULI SIGNIFICANCE}

The nonlinearity challenge concerns the fact that similarity of molecular structures is often not closely correlated with similarities of olfactory phenomenology. Unfortunately for the molecular structure theory, it does not have resources to fully provide a representational account of this situation. For instance, the fact that of two significantly similar structures only one causes experiences of urinous odour cannot be explained by referring to differences in ratios, concentrations, or organisational factors such as grouping, since the relevant phenomenal differences occur even if such factors are held constant. In consequence, one may doubt whether olfactory experiences track the molecular composition of olfactory plumes as then similar structures should be phenomenally experienced in a similar way. In fact, critics of the representational approaches to olfaction usually point out that the presence of a 
nonlinearity challenge suggests that the main function of olfaction is not to represent the physical features of stimuli but to recognise the significance of the stimulation for the organism (see Keller, 2016, pp. 108-109, 129). For instance, the olfactory phenomenology is in an important aspect determined by recognising whether the perceived stimuli are harmful or beneficial. Because dissimilar molecular structures can be similar in terms of their significance for the organism, and similar structures may significantly differ in this respect, nonlinearity occurs since similar structures may be experienced differently due to their distinct significance.

The above observation does not entail the experienced olfactory valence being completely unrelated to the molecular structure of stimuli. Actually, the contemporary models of olfactory perception demonstrate that a significant portion of variation in valence may be explained by reefing to structural properties of molecules (Secundo et al., 2014; Snitz et al. 2013). In consequence, it may be claimed that in many cases valence is a property of stimulus - or at least supervenes on its structural properties. Of course, such a situation is perfectly consistent with the molecular structure theory. However, it is also well-established that the experienced olfactory valence is also determined by other factors such as memories, expectations, or context in which a stimulus is presented (Haddad, 2010; Wilson and Stevenson, 2006). In fact, Young (2016) acknowledges that such factors influence the olfactory valence and may refer to them as an explanation of nonlinearity between structural variations of stimuli and evaluative, phenomenal variations in experiences. However, to succeed as a representational account of olfaction, the molecular structure theory has to do something more. Namely, it has to provide a representational interpretation of changes in evaluative phenomenal character — which are unrelated to changes in perceived stimuli-by showing that they are determined by changes in representational content of olfactory experiences. Nevertheless, the current version of the molecular structure theory, which 
characterises representational content in terms of molecular composition, rations, intensity, and perceptual organization, does not provide such interpretation.

In case of the independency challenge, the molecular structure theory can successfully provide a representationalist explanation of many examples aimed to show an olfactory phenomenal difference that is not determined by a difference in content. For example, the fact that the same chemical stimuli can be experienced differently when presented alone and when presented in a mixture with other odorants is predicted by the molecular structure theory. According to the theory the olfactory phenomenal character depends on the composition of an olfactory plume and on ratios between structures. In consequence, a plume composed solely of X-structured molecules is likely to be experienced differently than a plume in which structures $\mathrm{X}$ and $\mathrm{Y}$ are present.

Furthermore, the representational framework of molecular structure theory can account for individual differences in olfactory phenomenology as this theory does not require that every person has to represent all olfactory stimuli in the same way. For instance, due to physiological differences people may differ in their sensitivity to X-structured molecules such that a certain combination containing both $\mathrm{X}$ and $\mathrm{Y}$ structures may be represented as composed solely of $\mathrm{Y}$ by one person and represented as composed both by $\mathrm{X}$ and $\mathrm{Y}$ by another person. As a result, despite the sameness of actual physical stimulus, representational contents and phenomenal characters will differ in the case of each person.

More problematic cases are those in which olfactory phenomenology changes in virtue of top-down influences which occur due to expectations evoked by a propositional stimulus. A relevant example is provided by a Herz and von Clef (2001) study in which people were presented with olfactory stimuli such that the same stimulus could be presented either with a verbal label associated with positive or negative hedonic value in order to activate distinct beliefs and expectations concerning the stimulus. For instance, pine oil was presented with a 
positive 'Christmas tree' label or with a negative 'spray disinfectant' label. It was observed that when the same stimulus is presented with differing labels, the majority of participants do not recognise its sameness and claim that two distinct substances were presented. Furthermore, negatively and positively associated labels influence the perceived olfactory valence such that the same stimuli with positive labels is judged as being more pleasant than when provided with a negative label.

To account for such results, a proponent of the molecular structure theory has to provide a representational explanation of phenomenal changes related to the fact that people have differing experiences of the same stimuli when having distinct label-related expectations, and that part of this phenomenal difference concerns the experienced pleasantness. When olfactory phenomenal character changes in virtue of attributing a variety of labels, the physical stimulus remains the same and so there are no differences in content regarding presence of molecular structures, their rations, and concentrations. Furthermore, the phenomenal changes introduced by labels are unlikely to concern differences in organisational relations associated with phenomena of grouping or figure/ground discrimination.

Nevertheless, a proponent of the molecular structure theory can still attempt to provide a representational solution by postulating that distinct labels evoke distinct expectations which, in effect, determine the aspects of an olfactory stimulus that are represented in a more detailed way and those that obtain merely a rudimentary representation. For instance, when a stimulus composed of structures $\mathrm{X}$ and $\mathrm{Y}$ is given a label ' $\mathrm{A}$ ', the structure $\mathrm{X}$ may be represented in a more detailed way than the structure $\mathrm{Y}$ and, as a result, the $\mathrm{XY}$-mixture is more likely to be recognised as A-odour. When a label ' $\mathrm{B}$ ' is given, the situation is reversed: The $\mathrm{XY}$-mixture is more likely to be recognised as B-odour because the $\mathrm{X}$ structure is represented in a more rudimentary way than the Y structure. In consequence, in each case the 
representational content would be distinct, determining the differences in phenomenal character.

However, even if such a representational explanation is valid, it is unlikely to properly account for a difference in olfactory valence introduced by labels, because it is unclear why changes in representational precision should result in experiencing a chemical stimulus in a pleasant or an unpleasant way. The same is true about other factors available for a proponent of the molecular structure theory. According to the representationalist position, sensory phenomenology should be wholly determined by representational content, but it is not obvious why differences in represented molecular structures, their ratios, or concentrations should result in differences in experienced olfactory valence. In consequence, the molecular structure theory has problems with accounting for those variants of independency challenge which concern evaluative olfactory phenomenology.

According to the above considerations, both nonlinearity challenges and independence challenges demonstrate that the molecular structure theory lacks the resources for providing a representational account of phenomenal changes resulting from a difference in the significance of olfactory stimuli for a subject. It is an important problem as in case of olfaction the evaluative aspects are by no means peripheral. In particular, scientists and philosophers investigating human olfaction often claim that odour perception is largely a perception of valence (Yeshurun \& Sobel, 2010), which is one of the main descriptors used in characterising olfactory stimuli (Khan et al., 2007), and olfactory mechanisms are closely associated with emotional responses (Keller 2016, pp. 123-128; Soundry et al., 2011; Stevenson, 2009). In fact, there are studies suggesting that, while in vision the retina is organised such that nearby fragments respond to stimuli coming from similar spatial directions, in audition nearby fragments of cochlea respond to similar sound frequencies; in the case of olfaction nearby fragments of olfactory epithelium respond to stimuli of similar 
valence (Lapid et al., 2011). In consequence, in its current versions the molecular structure theory leaves a crucial aspect of olfactory experiences without representational explanation.

It should be noted that the above problems are not specific to the molecular structure theory, but affect all the current major representational theories of olfaction. The main representational alternatives to the molecular structure theory are odour theories, according to which, what is represented in olfactory experiences are odours which, depending on a specific approach, are characterised as spatiotemporally extended individuals (e.g., Millar, 2019; O'Callaghan 2016) or properties of the subject's surroundings (e.g., Batty 2010). However, it is not obvious what individuate such odours. If they are individuated in reference to the molecular composition, then odour theories are variants of the molecular structure theory and are likely to inherit its problems. On the other hand, if the odours' individuation is left unspecified, then odour theories do not have resources to provide any exact answer for the nonlinearity and independency challenges. ${ }^{1}$

Sometimes the odour theories are combined with a layered view of olfactory content which states that olfactory experiences represent not only odours, but also objects that are odours' sources (see Lycan, 2014). While this proposal may account for some additional variations in phenomenology, as representations of the same combinations of molecular structures may have distinct phenomenal characters if they are accompanied by contend specifying distinct sources, it is also problematic. First, there are reasons, connected both with the olfactory phenomenology (Batty, 2010) and the information available to the olfactory system (Keller, 2016, pp. 75-77) for rejecting a proposal that olfaction represents odours' sources. Second, it is not clear how the introduction of content specifying odours' sources can

\footnotetext{
${ }^{1}$ The analogous problem occurs in the case of the stuff theory proposed by Mizrahi (2014), according to which entities represented in olfactory experiences belong to the ontological category of 'stuffs' usually denoted by mass nouns.
} 
account for variations in evaluative olfactory phenomenology. This is because merely representing the presence of a certain object does not, by itself, provide any information about the significance of this object for a subject.

Subsequently, I propose a solution to the problems threatening representational approaches to olfaction by extending the molecular structure theory by a representational account of olfactory valence and other factors regarding the significance of stimuli.

\section{OLFACTORY EVALUATIVISM}

The authors who develop representational accounts of sensory pleasure postulate that evaluative sensory states represent their object as having a negative or positive evaluative property. For instance, it may be proposed that sensory displeasure consists of representing a certain object as being bad for the subject while sensory pleasure consists of attributing a property of being good for the subject (see Bain, 2014; Cutter \& Tye, 2011; Gray, 2014; Nelkin, 1994 for variants). One of the most influential representational theories of sensory pleasure is "evaluativism," originally developed as a theory of pain's unpleasantness. According to evaluativism, experiences of pain attribute both some non-evaluative properties, for instance that there is a disturbance in a bodily location, and negative evaluative properties, for example that the considered disturbance is bad for a subject. Such evaluative properties are relational ones which concern the positive or negative significance of a certain object for a given subject. For instance, Bain (2013), one of the main proponents of evaluativism, provides the following characterisation of experiences of pain: 
Pain evaluativism: A subject's being in unpleasant pain consists in his (i) undergoing an experience that represents a disturbance of a certain sort, and (ii) that same experience additionally representing the disturbance as bad for him.

Below, I argue that the idea expressed by pain evaluativism can be applied to extend the molecular structure theory and obtain the "olfactory evaluativism" which can successfully answer the nonlinearity and independence challenges. In doing so I do not justify that the evaluativism is the true theory of evaluative sensory characteristics. There is a wide discussion concerning its advantages and problems which goes beyond the scope of this paper (e.g., Aydede \& Fulkerson, 2019; Bain, 2019; Brady, 2015). Furthermore, I do not aim to prove that the olfactory evaluativism is a true theory of olfactory evaluative aspects. In particular, there are many alternative accounts of sensory pleasure which characterise evaluative sensory states, inter alia, in terms of desires or commands (e.g., Bramble, 2013; Heathwood, 2007; Klein, 2015; Marinez, 2015).

Nevertheless, I provide reasons showing that olfactory evaluativism not only provides a representational solution to the nonlinearity and independency challenges, but also that it is a serious candidate for being an accurate approach to those aspects of olfaction which concern the significance of stimuli for a subject. In consequence, olfactory evaluativism provides a framework in which representational accounts of human olfaction can be further developed.

The proposed olfactory evaluativism, in an analogy to classic pain evaluativism, postulates that olfactory experiences represent both nonevaluative and evaluative, relational properties of a chemical stimulus. Because olfactory evaluativism is an extension of the molecular structure theory, it preserves its insight that olfactory experiences represent molecular structures, their ratios and concentration within the olfactory plume, and their organisation regarding grouping and figure/ground distinction. However, olfactory 
evaluativism supplements the molecular structure theory by a statement that nonevaluative elements specified by the molecular structure theory are also represented as having evaluative, relational properties which concern the significance of a stimulus for a subject.

Philosophers developing representational theories of sensory pleasure have proposed several ideas concerning the content of such evaluative properties. For instance, the negative evaluative property has been characterised as a property of being bad for a subject (Bain, 2014), as being bad for a subject to degree X (Cutter \& Tye, 2011), as being negatively significant (Gray, 2014), or as being harmful (Nelkin, 1994). Furthermore, evaluative properties may concern not only the significance of the stimuli itself but also the associations between stimuli and other objects, positively or negatively significant for a subject, as well as the actions that are suitable, or should be avoided, in the presence of a given stimulus. For instance, a stimulus may be evaluated as being such that its occurrence is likely to be associated with the presence of food, i.e. an object which has a positive significance, and that the suitable action — given the presence of these stimuli—is some form of tracking behaviour.

Overall, the evaluative olfactory properties are those which (a) concern the positive or negative significance of a stimulus for a subject, (b) concern the association of a stimulus with the presence of positively or negatively significant objects, and (c) concern actions which are suitable or not when a stimulus is present. It is plausible that human olfaction has the ability to represent a wide variety of such evaluative properties, since olfactory mechanisms are involved in the processing of emotions and influenced by the mechanisms responsible for memory and learning. In particular, structures relevant for olfactory processing such as the amygdala and the olfactory bulb are engaged in processing olfactory stimuli and emotions, and, in consequence, play a role in motivating emotionally based behaviours (e.g. avoidance behaviours occurring due to felt disgust, see Jin et al., 2015; Keller, 2016, pp. 123-130; Root et al., 2014; Winston et al., 2005, see also Syrjänen et al., 2021 for olfactory influences on 
face evaluation). Therefore, it is likely that olfaction can ascribe to chemical stimulus properties regarding its positive or negative significance and recognise actions that are suitable, given the emotionally laden stimulus. Furthermore, it is well established that the way in which people experience olfactory stimuli is shaped by previous experiences with objects, in particular food related (see De Houwer et al., 2001; Wilson \& Stevenson, 2006, pp. 135137), and olfaction uses multimodal, contextual cues in order to recognise a given odour (Porada et al., 2019).

Relying on the above considerations, the olfactory evaluativism can be characterised as follows:

Olfactory evaluativism: Olfactory experiences represent (i) molecular structures composing an olfactory plume as well as their ratios, concentrations, and organisational factors (i.e., regarding figure/ground status and grouping), and (ii) that elements specified in (i) have relational, evaluative properties concerning their positive or negative significance, their associations with positively or negatively significant objects, and actions that are suitable or not given their presence.

The first question that should be asked regarding olfactory evaluativism is whether this position is a tracking representationalist theory of olfactory experiences. As specified in section one, in order to be such a theory, it has to satisfy both phenomenal and content determination theses. The satisfaction of the phenomenal determination thesis does not pose any problem for olfactory evaluativism. Similarly, as in the molecular structure theory, phenomenal character of olfactory experiences is determined by representational content, but in the case of olfactory evaluativism this content concerns also evaluative, relational properties. However, it may seem that olfactory evaluativism has a problem with satisfying 
the content determination thesis. According to this thesis, content of a representation is determined by a systematic relation between occurrences of a given representation and the presence of certain elements in the environment influencing the perceptual system.

More precisely, a representation $\mathrm{R}$ represents those elements which, in some optimal conditions, cause R to occur. Nevertheless, it seems that in the case of olfactory experiences, the same stimulus, having the same properties, can be evaluated differently in a way that cannot be explained by postulating representational errors arising from suboptimal conditions. For instance, a person may experience a milk odour as being pleasant, but later, after being sick as a result of drinking milk, may experience the same odour as disgusting. In such a case the same stimulus is represented as having different, incompatible evaluative properties, but it does not seem that any of these representations is an example of a representational error.

In consequence, one may suspect that there is no systematic relation between occurrences of evaluative olfactory representations and the presence of olfactory stimuli. This is because even in optimal conditions the same stimulus, with the same properties, can be without an error, represented as having distinct evaluative properties. In other words, in optimal conditions the same stimulus $\mathrm{S}$ can cause an accurate evaluative representation $\mathrm{R}$ as well as an incompatible, accurate evaluative representation $\mathrm{R}^{\prime}$ and so it seems that the content of these representations has to be determined by some factor additional to the presence of $\mathrm{S}$.

However, such reasoning neglects the fact that stimuli with the same non-evaluative, chemical properties may, nevertheless, differ in possessed relational, evaluative properties which concern the positive or negative significance of an olfactory stimulus for the subject. Due to the relational character, the possession of an evaluative property by a stimulus depends not merely on its non-evaluative characteristics, such as molecular structure, but also on the characteristics of a subject experiencing the stimulus. Therefore, for a certain subject a milk odor may have a different relational evaluative property before milk-related sickness than 
after it as in each situation the characteristics of the subject are distinct. In particular, after sickness a subject has new associations and memories concerning milk odour.

As a result, both pre- and post-sickness representations can be considered accurate. They attribute distinct relational, evaluative properties and in fact in each case, despite the chemical sameness of stimulus, evaluative relational properties of the stimulus are distinct due to differences in the subject. In consequence, the systemacity of relation required by content determination thesis can be maintained. Olfactory representations have their evaluative content due to the fact that they, under optimal conditions, are caused by stimuli with relational, evaluative properties. However, the occurrence of these relational properties partially depends on the characteristics of the perceiving subject, so they may vary despite the sameness of non-evaluative, chemical properties of stimuli.

Having established that olfactory evaluativism is a form of tracking representationalism, it can be further asked whether this representational theory is able to overcome the problems related to the nonlinearity and independency challenges. In the case of the standard version of molecular structure theory, the nonlinearity objection threatens both the content determination thesis and the phenomenal determination thesis. If olfactory content is determined by systematic relations between occurrences of olfactory experiences and the presence of combinations of chemical structures in olfactory plumes, and further content determines phenomenal character, then it should be the case that phenomenal similarity correlates with similarity of represented molecular structures. However, the nonlinearity challenge shows that often this is not the case as similar chemical structures may lead to phenomenally distinct experiences and dissimilar structures may cause similar olfactory phenomenology. In consequence, doubt is cast that the content of olfactory experiences concerns the molecular composition of olfactory plumes and poses a question regarding the 
factors which determine phenomenal character such that phenomenal similarity does not correlate with structural similarity among perceived stimuli.

On the other hand, such lack of strict correspondence between similarity of represented structures and phenomenal similarity is not problematic, but in fact is predicted by olfactory evaluativism. While being representational, this approach can accommodate the insight of antirepresentationalists who claim that phenomenal character of olfactory experiences is, importantly, determined by the significance of the stimulus for an organism. This is because in the case of olfactory evaluativism, phenomenal similarity between olfactory experiences does not simply reflect similarity of represented structures, but is also determined by the represented evaluative, relational properties. In the case of olfactory evaluativism, it is expected that similar chemical structures, which nevertheless differ in significance, will be experienced differently as they will be represented as having distinct evaluative, relational properties.

Analogously, dissimilar structures may be experienced in a phenomenally similar way due to shared evaluative properties. For instance, while the standard version of the molecular structure theory has problems in accounting for the fact that of two similar structures only one is experienced as urinous, such cases or not challenging for olfactory evaluativism. According to this position, urinous phenomenal character is determined not merely by non-evaluative properties of chemical stimuli but also by the fact that it is represented, for example, as having a certain negative significance, as being associated with negatively evaluated objects such as bodily fluids, and as being such that the suitable actions concern avoidance rather than seeking the stimulus.

Similarly, olfactory evaluativism is not threatened by cases related to the independency challenge which are problematic for the molecular structure theory. In particular, the molecular structure theory has difficulties in explaining changes in experienced 
olfactory valence happening independently from changes in the molecular composition of an olfactory plume. However, according to the olfactory evaluativism, when such change happen, for instance because the same chemical stimulus is presented with differing labels evoking positive or negative associations, the evaluative olfactory phenomenology is likely to be different due to the fact that distinct evaluative properties are represented.

It seems that the standard version of the molecular structure theory does not have conceptual resources which showing that change in representational content underlines such phenomenal difference. On the other hand, no such problem is present in the case of the olfactory evaluativism. According to this approach, changes in evaluative phenomenology are not independent of changes in representational content but are determined by differences in represented evaluative, relational properties. In consequence, when new expectations are evoked, the evaluative content of an olfactory experience is modified, and as a result the phenomenal character also undergoes changes concerning its evaluative aspects. As mentioned earlier, such a change in evaluative content may happen despite the sameness of non-evaluative properties of chemical stimuli, since evaluative properties are relational properties whose occurrence partially depends on the characteristics of a subject, for instance those concerning possessed expectations.

It should be noted that the olfactory evaluativism not only constitutes an improvement of the molecular structure theory but, as argued in section 3, provides solutions for problems common to all major representational theories of olfaction. Furthermore, proposing a specific theory of olfactory valence also provides an answer to a question which has not been adequately answered by the authors preferring a non-representational view of olfaction. This is because the evaluative aspects of olfaction is usually used in a negative way (Barwich, 2018, 2019; Keller, 2016), to demonstrate problems for represenatationalism, without proposing a non-representational account of olfactory valence. 


\section{PLAUSIBILITY OF EVALUATIVISM}

The above considerations show that olfactory evaluativism is a representational theory that can omit the major challenges facing the molecular structure theory. However, we should still ask whether there are any reasons to suppose that the olfactory evaluativism is a proper theory in the case of human olfaction. As stated earlier, I do not attempt to prove that the representational approach to olfactory evaluative aspects is the right one, and all other major types of theories, such as attitudinal (e.g., Heathwood, 2007), imperative (e.g., Martinez, 2015), and felt qualities theories (e.g., Bramble, 2013) of sensory evaluation cannot be applied in the considered context. However, below I present reasons why the evaluativist framework should be treated as one of the important contenders in the debates concerning olfactory experiences.

According to the olfactory evaluativism, there are two components of representational content which determine the phenomenal character of olfactory experiences: a component specifying non-evaluative properties of stimuli, mainly concerning molecular composition, and a component specifying relational, evaluative properties. In consequence, the olfactory evaluativism seems to predict an empirical pattern in which stimuli that are similar in nonevaluative properties but dissimilar in evaluative ones, or vice versa, should tend to be similar in some phenomenal aspects while differing in others. Because, as discussed in section 3, evaluative properties often supervene on non-evaluative ones, the cases of divergence between similarity of evaluative and non-evaluative properties are most likely associated with influences of factors such as memories or expectations. In fact, recent data suggest the presence of a pattern predicted by the olfactory evaluativism. These results come from the experiments by Bae and colleagues (Bae et al., 2019) who replicated the studies regarding the 
influence of verbal descriptions on olfactory phenomenology by presenting isovaleric acid with positive and negative labels ("cheese" and "vomit"). However, they also conducted a detailed study regarding how the difference in labels influenced descriptors that people use in characterising the stimulus. Some descriptors have been observed to remain the same regardless of whether the stimulus is presented with a negative or positive label, while others undergo significant changes. Such results suggest that when relational, evaluative properties are modified by introducing a positive or negative label, but non-evaluative properties of stimuli are held constant, the olfactory experiences start to differ in some phenomenal aspects, but remain the same in others. While, of course, further studies are needed to confirm and generalise these observations, the above results suggest that the tendency predicted by the olfactory evaluativism may, in fact, occur.

While the olfactory evaluativism predicts a general tendency for stimuli with similar non-evaluative properties to be phenomenally similar in some respect and stimuli with similar evaluative properties to be phenomenally similar in some other respect, the proposed position does not mean that it must the case in every particular example. To demonstrate this, let's consider olfactory examples proposed by Pautz $(2010,2014)$ as a part of his general criticism of tracking representationalism. He argues that (a) there are structurally dissimilar stimuli which give a very similar quality, for instance "pineapple"; (b) there are structurally similar stimuli, but only some of them give a similar quality, for instance "musk"; (c) the changes of stimulus concentration may not merely change its experienced intensity but also significantly modify its qualitative character.

In consequence, there seem to be cases in which similarity of non-evaluative properties is not associated with any salient phenomenal likeness, and dissimilarity of such properties is not associated with phenomenal distinctions. Nevertheless, such counterexamples are not fatal for the olfactory evaluativism as this position does not entail 
anything about the relative impact of non-evaluative and evaluative content on phenomenology in any particular case. For instance, in the case of distinct structures giving the "pineapple" experience, the phenomenal impact of similar evaluative properties, connected with representing the same positively significant, edible item, may be much larger than the phenomenal impact of distinct non-evaluative properties. Analogously, phenomenal aspects determined by non-evaluative, structural similarities may be overshadowed by the influence of distinct evaluative properties. This is not to deny that, in the above cases, similarity and dissimilarity of non-evaluative properties may influence phenomenology, but this impact may be more subtle and require detailed investigations (such as those conducted by Bae et al., 2019) in order to be discovered.

Furthermore, because the occurrence of evaluative, relational properties to an important degree depend on the presence of certain non-evaluative properties of chemical stimuli, it is likely that if olfactory evaluativism is true, then many evaluative properties will be represented after the non-evaluative properties have been processed by the olfactory mechanism. This prediction has been corroborated in studies by Olofsson and colleagues (2012, 2013, 2014). In one of these studies the task of participants was to decide whether an odour matches a provided label (like "lemon") or to judge whether the presented odour was pleasant or unpleasant. The time needed to complete each of these tasks was measured, and it was demonstrated that assessments of valence require more time (1100-1200 ms) than labelrelated identifications (1000 ms, see Olofsson et al., 2013). This suggests that valence is represented after the olfactory system had gained access to non-evaluative properties of a stimulus. The same pattern was revealed by using a distinct design in which the task was to judge whether (a) the second of two subsequently presented odours belonged to the same category as the first (e.g., if it was also a fish odour); or (b) the second odour was more pleasant than the first. Again, it was revealed that comparison of odours requires less time 
when a task involves identification, and more time when it involves valence assessment (Olofsson et al., 2012).

In addition, if olfactory evaluativism is true, then olfactory ascriptions of evaluative properties are representations which can be accurate or inaccurate. For instance, an unpleasant olfactory state may occur both due to the fact that an olfactory experience properly ascribes an evaluative property to a chemical stimulus and as a result of a misrepresentation when a negative evaluative property is incorrectly attributed to a stimulus which does not possess it. Such evaluative mistakes are likely to be costly as they may result in neglecting harmful stimuli or seeking stimuli which are not beneficial.

In consequence, it is plausible that the presence of evaluative olfactory representations, as characterised by olfactory evaluativism, is accompanied by mechanisms which minimise the risk of misrepresentation of valence. In particular, the evaluative mistakes are likely to occur if bottom-up processing of a stimulus does not provide an unambiguous representation of properties which serves as a basis for ascribing evaluative characteristics. Such ambiguity may be resolved, and risk of misrepresentation minimised, by using top-down processes which help in evaluating a stimulus by relying on states such as beliefs, expectations or memories concerning previous encounters with similar stimuli. Hence, if olfactory evaluativism is a correct account of olfactory experiences, it should be expected that higher-level mental states frequently influence and modify olfactory ascriptions of valence. This conviction is additionally supported by the fact that evaluative properties are relational properties partially depending on characteristics of the perceiving subject. In consequence, changes in ascribed evaluative properties are likely to be partially determined by changes in a subject's states such as beliefs and memories.

In fact, it is well-established that non-perceptual mental states have an impact on olfactory assessments of valence. Earlier, in discussing the study by Herz and von Clef (2001) 
(see also Barwich, 2019 for additional similar examples), I presented evidence showing that beliefs and expectations invoked by verbal labels are able to significantly change valence such that the same stimuli may be experienced, depending on provided label, as pleasant or unpleasant. There is also rich evidence showing the diachronic changes in perceived olfactory valence happening due to gaining memories related to previous encounters with chemical stimuli (see Stevenson et al., 2010; Wilson \& Stevenson, 2006). For instance, it is observed that as odours become more familiar they also become more pleasant (Rabin \& Cain, 1989) or more neutral (Cain \& Johnson, 1978). Similarly, the olfactory assessment of valence is determined by previous associations with food (De Houwer et al., 2001).

Furthermore, during lifetime, due to an increase in the number of olfactory experiences of a variety of odorants, olfactory evaluative assessments become more diverse, and extreme evaluations become more common (Stevenson \& Repacholi, 2003). Such evidence shows that the significance of olfactory stimuli is established not merely relying on bottom-up processing of stimuli but in an important way depending on input from higherorder processes concerning, inter alia, beliefs and memories. This is what is expected if, as postulated by olfactory evaluativism, assessments of valence are representations that may be accurate and inaccurate as additional, top-down input helps in avoiding evaluative mistakes. Furthermore, determination of assessments of olfactory valence by higher-level mental states is also likely if evaluative properties are relational properties which are partially determined by characteristics of a perceiving subject, since such characteristics plausibly concern the subject's beliefs and memories.

As stated earlier, the above considerations do not justify olfactory evaluativism as a right philosophical theory of olfactory evaluative aspects. In particular, it may be the case that a non-representational theory of olfactory evaluation, can also accommodate the top-down influences on valence assessment, and the fact that valence is often recognised after 
processing of non-evaluative properties of stimuli. However, my considerations show that olfactory evaluativism is coherent with important characteristics of human olfactory processing of evaluative information, so adherents of representationalism possess a serious theoretical option which overcomes challenges faced by the original molecular structure theory.

\section{CONCLUSIONS}

Accommodating the evaluative components of olfaction poses a serious problem for the representational theories of perceptual experiences. In fact, the most developed representational theory of olfaction, the molecular structure theory, is not able to account for nonlinearity and independency challenges concerning evaluation of olfactory stimuli. However, despite these problems, the representational approach to olfaction can be saved by making a certain extension of the molecular structure theory. According to this extended version, named "olfactory evaluativism," olfactory experiences represent both non-evaluative properties of stimuli and evaluative, relational properties. This representational theory not only overcomes the challenges faced by the molecular structure theory but is also consistent with major facts regarding the way in which valence is perceived in the case of human olfaction, so it can serve as a basis for further developments of the representational approach to olfactory experiences.

\section{ACKNOWLEDGEMENTS}

The author would like to thank the anonymous reviewers for their comments.

\section{REFERENCES}


Aasen, S. (2019). Spatial aspects of olfactory experience. Canadian Journal of Philosophy, 49(8), 1041-1061.

Aydede, M., \& Fulkerson, M. (2019). Reasons and theories of sensory affect. In Bain, D., Brady, M., \& Corns, J., (Eds.), The philosophy of pain: Unpleasantness, emotion, and deviance (pp. 27-59). New York, NY: Routledge.

Bae, J., Yi, J.-Y., \& Moon, C. (2019). Odor quality profile is partially influenced by verbal cues. PLoS ONE, 14(12), e0226385.

Bain, D. (2013). What makes pains unpleasant?. Philosophical Studies, 166, 69-89.

Bain, D. (2014). Pains that don't hurt. Australasian Journal of Philosophy, 92(2), 305-320.

Bain, D. (2019). Why take painkillers?. Nous, 53(2), 463-490.

Barwich, A.-S. (2018). Measuring the world. Olfaction as a process model of perception. In Nicholson, D. J., \& Dupre, J. (Eds.), Everything flows: Towards a processual philosophy of biology (pp. 337-356). Oxford: Oxford University Press.

Barwich, A.-S. (2019). A critique of olfactory objects. Frontiers in Psychology, 10, 1337. https://doi.org/10.3389/fpsyg.2019.01337

Barwich, A.-S. (2020). Smellosophy. What the nose tells the mind. Cambridge, MA: Garvard University Press.

Batty, C. (2010). A representational account of olfactory experience. Canadian Journal of Philosophy, 40, 511-538.

Brady, M. S. (2015). Feeling bad and seeing bad. Dialectica, 69(3), 403-416.

Bramble, B. (2013). The distinctive feeling theory of pleasure. Philosophical Studies, 162, $201-217$.

Cain, W. S., \& Johnson, F. (1978). Lability of odor pleasantness: Influence of mere exposure. Perception, 7, 459-465. 
Castro, J. B., \& Seeley, W. P. (2014). Olfaction, valuation, and action: reorienting perception.

Frontiers in Psychology, 5, 299. https://doi.org/10.3389/fpsyg.2014.00299

Cooke, E., \& Myin, E. (2011). Is trilled smell possible? How the structure of olfaction determines the phenomenology of smell. Journal of Consciousness Studies, 18(11-12), 5995.

Cutter B., \& Tye, M. (2011). Tracking representationalism and the painfulness of pain. Philosophical Issues, 21(1), 90-109.

De Houwer, J., Thomas, S., \& Baeyens, F. (2001). Associative learning of likes and dislikes: A review of 25 years of research on human evaluative conditioning. Psychologicla Bulletin, $127,853-869$.

Frumin, I., Sobel, N., \& Gilad, Y. (2013). Does a unique olfactory genome imply a unique olfactory world?. Nature Neuroscience, 17(1), 6-8.

Gottfried, J. A. (2010). Central mechanism of odour object perception. Nature Reviews Neuroscience, 11, 628-641.

Gray, R. (2014). Pain, perception and the sensory modalities: Revisiting the intensive theory. Review of Philosophy and Psychology, 5, 87-101.

Green, E. J. (2016). Representationalism and perceptual organization. Philosophical Topics, 44(2), 121-148.

Haddad, R., Medhanie, A., Roth, Y., Harel, D., \& Sobel, N. (2010). Predicting odor pleasantness with an electronic nose. PLoS Computational Biology, 6(4), e1000740.

Heathwood, C. (2007). The reduction of sensory pleasure to desire. Philosophical Studies, $133,23-44$.

Herz, R. S., \& von Clef, J. (2001). The influence of verbal labeling on the perception of odors: Evidence for olfactory illusions?. Perception, 30, 381-391. 
Hutto, D. D., \& Myin, E. (2013). Radicalizing enactivism: Basic minds without content. Cambridge, MA: The MIT Press.

Jin, J., Zelano, C., Gottfried, J. A., \& Mohanty, A. (2015). Human amygdala represents the complete spectrum of subjective valence. The Journal of Neuroscience, 35(45), 15145-15156. Keller, A. (2016). Philosophy of olfactory perception. New York: Palgrave Macmillian.

Khan, R. M., Luk, C.-H., Flinker, A., Aggarwal, A., Lapid, H., Haddad, R., \& Sobel, N. (2007). Predicting odor pleasantness from odorant structure: Pleasantness as a reflection of the physical world. The Journal of Neuroscience, 27(37), 10015-10023.

Klein, C. (2015). What the body commands: The imperative theory of pain. Cambridge, MA: MIT Press.

Lapid, H., Shushan, S., Plotkin, A., Voet, H., Roth, Y., Hummel, T., Schneidman, E. \& Sobel, N. (2011). Neural activity at the human olfactory epithelium reflects olfactory perception. Nature Neuroscience, 14(11), 1455-1463.

Lycan, W. (1996). Consciousness and experience. Cambridge, MA: MIT Press.

Lycan, W. (2014). The intentionality of smell. Frontiers in Psychology, 5(436), doi:10.3389/fpsyg.2014.00436.

Martinez, M. (2015). Disgusting smells and imperativism. Journal of Consciousness Studies, 22(5-6), 191-200.

Millar, B. (2019). Smelling objects. Synthese, 196, 4279-4303.

Millikan, R. G. (1989). In defense of proper functions. Philosophy of Science, 56(2), 288302.

Mizrahi, V. (2014). Sniff, smell, and stuff. Philosophical Studies, 171(2), 233-250.

Miłkowski, M. (2015). The hard problem of content: solved (long ago). Studies in Logic, Grammar and Rhetoric, 41(1), 73-88.

Nanay, B. (2010). Attention and perceptual content. Analysis, 70, 263-270. 
Nelkin, N. (1994). Reconsidering pain. Philosophical Psychology, 7(3), 325-343.

O’Sullivan, B., \& Schroer, R. (2012). Painful reasons: representationalism as a theory of pain. The Philosophical Quarterly, 62(249), 737-758.

Olofsson, J. K. (2014). Time to smell: a cascade model of human olfactory perception based on response-time (RT) measurement. Frontiers in Psychology, 5, 33. https://doi.org/10.3389/fpsyg.2014.00033.

Olofsson, J. K., Bowman, N. E., \& Gottfried, J. A. (2013). High and low roads to odor valence?. A choice response-time study. Journal of Experimental Psychology: Human Perception and Performance, 39, 1205-1211.

Olofsson, J. K., Bowman, N. E., Khatibi, K., \& Gottfried, J. A. (2012). A time-based account of the perception of odor objects and valences. Psychological Science, 23, 1224-1232.

Pautz, A. (2010). Do theories of consciousness rest on a mistake?. Philosophical Issues, 20, $333-367$.

Pautz, A. (2014). The real trouble with phenomenal externalism: New empirical evidence for a brain-based theory of consciousness. In Brown, R. (Ed.), Consciousness inside and out: Phenomenology, neuroscience, and the nature of experience (pp. 237-298). Dordrecht: Springer.

Peacocke, C. (1983). Sense and content: Experience, Thought and their relations. New York: Oxford University Press.

Peacocke, C. (1992). A study of concepts. Cambridge, MA: MIT Press.

Porada, D. K., Regenbogen, C., Seubert, J., Freiherr, J., \& Lundström, J. N. (2019). Multisensory enhancement of odor object processing in primary olfactory cortex. Neuroscience, 418, 254-265. 
Rabin, M. D., \& Cain, W. S. (1989) Attention and learning in the perception of odor mixtures. In Laing, D. G., Cain, W. S., McBride, R. L., \& Ache, B. W. (Eds.), Perception of complex smells and tastes (pp. 173-188). Sydney: Academic Press.

Root, C. M., Denny, C. A., Rene, H., \& Axel, R. (2014). The participation of cortical amygdala in innate, odour-driven behavior. Nature, 515, 269-273.

Siegel, S. (2010). Contents of visual experience, New York: Oxford University Press.

Secundo, L., Snitz, K., \& Sobel, N. (2014). The perceptual logic of smell. Current Opinion in Neurobiology, 25, 107-115.

Sell, C. S. (2006). On the unpredictability of odor. Angewandte Chemie, 45(38), 6254-6261.

Skrzypulec, B. (2021). The nonclassical mereology of olfactory experiences. Synthese, 198, 867-886.

Snitz, K., Yablonka, A., Weiss, T., Frumin, I., Khan, R.M., \& Sobel, N. (2013). Predicting odor perceptual similarity from odor structure. PLoS Computational Biology, 9(9), e1003184. Soudry, Y., Lemogne, C., Malinvaud, D., Consoli, S.-M., \& Bonfils, P. (2011). Olfactory system and emotion: Common substrates. European Annals of Otorhinolaryngology, 128, 1823.

Stevenson, J. (2009). Phenomenal and access consciousness in olfaction. Consciousness and Cognition, 18, 1004-1017.

Stevenson, R. J., Oaten, M. J., Case, T. I., Repacholi, B. M., \& Wagland, P. (2010). Children's response to adult disgust elicitors: Development and acquisition. Developmental Psychology, 46(1), 165-177.

Stevenson, R. J., \& Repacholi, B. M. (2003). Age related changes in children's hedonic response to male body odor. Developmental Psychology, 39, 670-679.

Stevenson, R. J., \& Wilson, D. A. (2007). Odour perception: An object-recognition approach. Perception, 36, 1821-1833. 
Syrjänen, E., Fischer, H., Liuzza, M. T., Lindholm, T., \& Olofsson, J. K. (2021). A review of the effects of valenced odors on face perception and evaluation. i-Perception, 12(2), 1-19.

Trimmer, C., Keller, A., Murphy, N. R., Snyder, L. L., Willer, J. R., Nagai, M. H., et al. (2019). Genetic variation across the human olfactory receptor repertoire alters odor perception. PNAS, 116, 9475-9480.

Tye, M. (2002). Visual qualia and visual content revisited. In Chalmers, D. (Ed.), Philosophy of mind: Classical and contemporary readings (pp. 447-456). Oxford: Oxford University Press.

Wilson, D. A., \& Stevenson, R. J. (2006). Learning to smell: olfactory perception from neurobiology to behavior. Baltimore: The John Hopkins University Press.

Winston, J. S., Gottfried, J. A., Kilner, J. M., \& Dolan, R. J. (2005). Integrated neural representations of odor intensity and affective valence in human amygdala. The Journal of Neuroscience, 25(39), 8903-8907.

Wu, W. (2011). What is conscious attention?. Philosophy and Phenomenological Research, 82(1), 93-120.

Wu, W. (2014). Attention. New York: Routledge.

Yeshurun, Y., \& Sobel, N. (2010). An odor is not worth a thousand words: from multidimensional odors to unidimensional odor objects. Annual Review of Psychology, 61, $219-241$.

Young, B. D. (2016). Smelling matter. Philosophical Psychology, 29(4), 520-534.

Young, B. D. (2019). Smelling molecular structure. In Shottenkirk, D., Gouveia, S., \& Curado, J. (Eds.), Perception, cognition, and aesthetics (pp. 64-84). New York: Routledge Press.

Young, B. D. (2020). Perceiving smellscapes. Pacific Philosophical Quarterly, 101(2), 203223. 